\title{
El nacionalismo catalán y autonomía relativa del Estado: un análisis del proceso secesionista
}

Sebastián Zambelli

UNED. España. ${ }^{1}$

Artículo científico. Material original autorizado para su primera publicación en el Journal de Ciencias Sociales, Revista Académica de la Facultad de Ciencias Sociales de la Universidad de Palermo.

Recibido: 2-7-2015

Aceptado: 2-10-2015

Resumen:

A partir de la propuesta teórica de G. Therborn, este artículo analiza los elementos que amplían la autonomía relativa del Estado como explicación a la apuesta, por la secesión de España, de las élites políticas nacionalistas de la Comunidad Autónoma de Cataluña; y bajo qué condiciones operan esos elementos condicionantes. Esta explicación se inscribe como complementaria a la explicación de naturaleza instrumental de Miley y Martínez-Herrera respecto del proceso soberanista en Cataluña. La hipótesis es que los elementos que amplían la autonomía del Gobierno catalán son los cambios en las funciones de mediación y representación producidos por un giro en las bases sociales en que se apoyaba el partido político CiU.

Palabras clave: Proceso soberanista, Cataluña, Autonomía relativa del Estado, clase social.

Abstract:

From the theoretical proposal of $G$. Therborn, this article analyzes the elements that increase the relative autonomy of the state as an explanation for the bet, for secession from Spain, by the nationalist political elites in Catalonia. And under what conditions these determining elements operate. This explanation is complementary to the instrumental explanation of Miley and Martinez-Herrera in respect of the sovereignty process in Catalonia. The hypothesis is that the elements that extend the autonomy of the Catalan government are the changes in the functions of mediation and representation produced by a change in the social bases of the political party CiU.

Keywords: Sovereigntist Process, Catalonia, Relative Autonomy of the State, social class

\footnotetext{
${ }^{1}$ Sebastián Zambelli es politólogo por la UBA (Argentina), Master en Política y Democracia por la UNED, en el que fue premio "Fin de Máster 2009”; es en la actualidad Doctorando Becario FPI en la UNED donde desarrolla su tesis doctoral sobre el nacionalismo catalán. Ha sido docente en seminarios en la UBA (Argentina), así como, profesor-tutor en la UNED (España). Correo electrónico: sebastianzambelli@gmail.com; szambelli@bec.uned.es
} 


\section{Introducción:}

La pregunta que intentará responder este artículo es: ¿qué ha posibilitado que las élites políticas nacionalistas catalanas hayan radicalizado sus posiciones nacionalistas llevando adelante el proceso soberanista en Cataluña, en contra de los intereses de los sectores dominantes a la que la élite política ha estado siempre especialmente vinculada? ¿En qué circunstancias han sido posibles esos cambios? La hipótesis que presenta este artículo sostiene que sólo a partir de la ampliación de la autonomía relativa producida por los cambios en las funciones de representación y mediación del Gobierno de la Generalitat -fruto de un giro en las bases sociales que lo sostienen y bajo unas condiciones económicas y sociales específicas de crisis - se hacen posibles los cambios en las élites nacionalistas en Cataluña.

\section{Marco teórico y metodológico. La cuestión central de la autonomía relativa y sus determinaciones.}

Dentro de la dinámica del famoso debate de Miliband ${ }^{2}$ y Poulantzas surgen, frente a las dos posturas que en principio parecían irreconciliables, una serie de intelectuales que intentaron sintetizar y $\operatorname{armonizar}^{3}$ las dos posiciones del debate, los instrumentalistas y los estructuralistas. Uno de esos esfuerzos -el más acertado según quién suscribe el presente- es el de Göran Therborn de su conocido libro ¿Cómo domina la clase dominante? La propuesta explicativa de Therborn propone una solución sintética de complementariedad de la perspectiva estructural y de la instrumental. Esta complementariedad, tal y como se verá, no es simétrica entre las dos aproximaciones; Therborn nos ofrecerá una aproximación estructural de naturaleza crítica con Poulantzas que, a su vez, incorpora la perspectiva de la agencia que propone el instrumentalismo de Miliband dentro del estructuralismo marxista.

\section{$\underline{\text { La Autonomía relativa del Estado }}$}

La autonomía relativa es la capacidad que tiene el Estado, en sus diferentes niveles de gobierno ${ }^{4}$, para poder tomar decisiones contrarias a la lógica de acumulación del Capital siempre a corto plazo; ello le permite al Estado (mediante el ejercicio de las tres funciones técnicas, políticas e ideológicas) la producción y reproducción del Modo de Producción, además de consolidar la posición dominante de las clases ${ }^{5}$ o fracción de clase hegemónica. Ello tiene dos efectos sobre las clases; el primero, es la consolidación de la dominación de una fracción de clase y la configuración de un "bloque de poder" (Poulantzas, 1978) y el

\footnotetext{
2 Para una revisión del debate véase Tarcus, (1991); Thwaites Rey (2007); Borón (2003); Codato y Perissinotto (2010); y Duhalde (2008).

3 Dentro de esa categoría se engloban autores como Block, (1980); Therborn, (1979) y Laclau y Mouffe (1987)

${ }^{4}$ Aquí se analizará el caso del gobierno regional de la Comunidad Autónoma de Cataluña.

${ }^{5}$ El tratamiento y la problematización de la cuestión de la clase social en tanto que concepto excede el marco del presente. Se sigue aquí el concepto de clase utilizado por Therborn, (1979; 1987), por coherencia teórica y por su potencial heurístico. Por otra parte, a los efectos de dar fluidez al texto, intentando no caer en repeticiones léxicas, se utilizan como sinónimos de clase los términos "sectores o segmentos". Therborn, define el concepto clase social "en términos estrictamente económicos, haciendo referencia a los «portadores» o «agentes» de determinadas relaciones de producción [en coherencia] con la tradición marxista clásica" (Therborn, 1987, p. 7).
} 
segundo, es la desorganización de las clases subordinadas, mediante la subordinación a los intereses de la fracción dominante que serán presentados como intereses generales para toda la sociedad, y por otra parte, a la concesión de ciertos reclamos sociales (Poulantzas, 1978, p. 50).

El límite estructural de la autonomía relativa estaría dado por la determinación - siempre en última instancia- de la base material del modo de producción. Estado y economía capitalista son interdependientes y se co-determinan mutuamente (Block, 1980; Therborn, 1979, 1987). Es por ello que uno de los límites de la autonomía relativa es el de la alteración de la lógica de acumulación del capital, pero siempre como ultima ratio.

Therborn (1979) explica la cuestión de la autonomía relativa del Estado en función de las relaciones de representación y mediación. Siguiendo la estela del estructuralismo poulantziano, se reconoce que el Estado, en cuanto tal, carece de poder en sí mismo y ese poder recae en la clase dominante, pero es a través del Estado como la clase ejerce el poder que posee "sobre otras clases y estratos" (Therborn, 1979, p. 218). Representación y mediación son los elementos condicionantes de la autonomía relativa del Estado o "la específica irreductibilidad del Estado a la dominación y la explotación extrapolíticas" (Therborn, 1979, p. 219). Si bien ambos procesos no extinguen las posibilidades de lo que sucede, en y a través del Estado, son aspectos analíticos profundamente relevantes para el análisis de la dominación.

Respecto a la mediación, Therborn entiende que "el Estado debe mediar la explotación o dominación de la clase dominante sobre las otras clases o estratos." (Therborn, 1979, p. 218). Esta mediación es una relación que involucra a tres elementos que son: "la clase dominante, el Estado y las clases dominadas, en la cual el principal problema es el que se refiere a la fuerza de las clases dominadas" (Therborn, 1979, p. 219).

Por representación Therborn entiende que "el Estado, y en especial su personal de más jerarquía, debe representar, es decir, promover y defender a la clase dominante y su modo de explotación o supremacía" (Therborn, 1979, p. 218). La referencia de "personal de más jerarquía" en tanto que personal político especializado claramente puede asimilarse a lo que aquí se entiende por la élite política. Esa relación social de representación vincula a la clase dominante con el Estado, incluyendo a las diferentes fracciones de clase, los agentes económicos y las élites.

Desarrollaremos nuestro análisis a partir del concepto de partido burgués ${ }^{6}$ (Therborn, 1979). El partido burgués moderno es a través del cual la clase dominante mediatiza sus posiciones a partir de la representación hacia los sectores burgueses, y además, estos partidos "pueden atraer también a la pequeña burguesía, a los estratos medios y a algunos sectores de la clase obrera sindicalizada" (Therborn, 1979, p. 231).

\footnotetext{
${ }^{6}$ El partido burgués es uno de los seis formatos específicos de las relaciones de representación que Therborn analiza para el Estado moderno.
} 
Ambas funciones estatales son interdependientes y van indisolublemente vinculadas. Representación y mediación operan conjuntamente; no obstante ello, se intentará discriminar analíticamente los cambios en las funciones comentadas en relación con las circunstancias socioeconómicas específicas.

Respecto del análisis de las circunstancias que amplían o limitan la autonomía relativa seguiremos el trabajo de Block (1980). Este autor detalla los contextos socioeconómicos que influyen en esa capacidad del Estado y señala que son tres los escenarios de incertidumbre que amplían la autonomía: la guerra, la depresión económica y la reconstrucción.

Siguiendo lo hasta aquí comentado, y para responder a la pregunta de investigación, se analizarán tres aspectos relacionados con la autonomía relativa en el caso del proceso soberanista catalán, estos son:

- La ampliación de la autonomía de la Generalitat de Cataluña a partir de los cambios en las mediaciones (es decir, un cambio en la forma de relación de la clase dominante, las clases dominadas y el Gobierno subcentral (Miliband, 1997)) y en la representación.

- Las condiciones que amplían o constriñen la autonomía relativa de la Generalitat de Cataluña

- Los límites de la autonomía relativa de la Generalitat de Cataluña

Estos tres elementos nos permitirán explicar cómo opera la autonomía relativa, y cómo a partir de la cual, la élite política puede tomar decisiones en contra de los intereses de la clase de la cual proviene; de ese modo podremos esclarecer cómo y en qué circunstancias, en el caso catalán, el propio Gobierno subcentral, en concreto la Generalitat de Cataluña, promueve la secesión de España.

\section{Claves de análisis para el caso de Cataluña:}

Para presentar brevemente la cuestión podemos decir que en la historia de la España constitucional, el nacionalismo catalán ha sido predominantemente pactista, es decir que la estrategia de las élites nacionalistas (principalmente la élite política conservadora) durante este tiempo fue la negociación y el acuerdo. Las élites políticas catalanas pactaban con el Estado central español más autonomía regional a cambio de apoyos legislativos a nivel nacional. Así ocurrió durante los gobiernos de González (1982-1996), Aznar (1996-2004) y Rodríguez Zapatero (2004-2011) (Dowling, 2013). En estos gobiernos se desplegaron una serie de transferencias y descentralizaciones que dotaron de un importante autogobierno a la comunidad autónoma de Cataluña. En este escenario el nacionalismo catalán de carácter independentista nunca superó cuotas de un 30\% de apoyo social (Miley, 2006).

A partir de la victoria del CiU en el año 2010 en las elecciones a la Generalitat, y de la sentencia del Tribunal Constitucional del mismo año, contraria en algunos aspectos a ciertos artículos del Estatuto de Autonomía 
de Cataluña reformado en el años 2006 durante el gobierno del Tripartito -y sumado a ello la llegada del Partido Popular al gobierno en el Estado Central en el año 2011- ese tradicional pactismo se ha ido transformando en secesionismo. Los apoyos sociales al independentismo han aumentado, impulsados por la radicalización de los discursos de las élites nacionalistas, desde el entramado institucional que apoya al nacionalismo y desde el Gobierno de la Generalitat (Miley, 2014; Alonso, 2015; Arza y Coll, 2014).

El Gobierno de CiU, apoyado por ERC, desde el año 2012, ha desarrollado una activa campaña de movilización a favor de lo que se conoce como el proceso soberanista. Este proceso pretende en última instancia la secesión de Cataluña de España y la herramienta para llevar a cabo la secesión es la celebración de un referéndum acerca de la independencia de Cataluña. Es a partir de aquí que la práctica totalidad de los discursos del nacionalismo catalán han abandonado el pactismo de antaño y han pasado a promover el secesionismo y el referéndum de independencia de Cataluña.

La actividad del Parlamento y del Gobierno regional catalán - casi en su totalidad- del mismo modo que las asociaciones en favor de la independencia y los partidos nacionalistas, se orientaron hacia la realización del referéndum de independencia. Para cumplir ese objetivo se desplegó una tenaz e incesante campaña de acciones, fundamentalmente de naturaleza simbólica, por parte de las instituciones mencionadas, encabezadas por CiU y apoyado por ERC. Finalmente el referéndum - bajo la forma de consulta popular y sin apoyo institucional alguno- se celebró el 9 de Noviembre de 2014, bajo circunstancias de excepción, ya que la legislación española prohíbe los referéndums que no convoque el Estado nacional.

¿Cómo se explica la radicalización de las posiciones nacionalistas desde la ciencia política? Existen dos aproximaciones generales que intentan dar cuenta del fenómeno del nacionalismo en Cataluña. Una, vinculada al nacionalismo, destaca como elemento explicativo de ese nacionalismo catalán una serie de elementos identitarios diferenciadores, como la lengua, la historia, el derecho, la cultura o el territorio (Etherrintong, 2003). Estos elementos constituirían lo que se denomina un hecho diferencial. Son esos hechos los que justifican el carácter de nación de Cataluña (Ovejero, 2006, 2012)

Miley (2013) sostiene que esta literatura politológica que estudia el nacionalismo catalán, tiende a desarrollar vías de encaje - desde cierta aproximación naturalizadora del nacionalismo o perennialista- de Cataluña en España al mismo tiempo que asume como un hecho sustantivo la nación catalana y, por otro lado, tiende a separarla del estudio y el análisis del movimiento nacionalista. De este modo el eje de sus investigaciones se pone en la necesidad del reconocimiento de la diversidad, hechos diferenciales, realidad nacional, etc., pero sin reparar - en no pocos casos - la propia diversidad hacia adentro de la sociedad 
catalana, por ejemplo, al entender de modo homogéneo la etnicidad, la identidad nacional, el uso de la lengua, etc. ${ }^{7}$

Esta aproximación del nacionalismo catalán entiende que el proceso soberanista se desarrolla a partir de la concepción de que "los partidos nacionalistas se han limitado a reaccionar a los cambios en la identidad y las preferencias de la ciudadanía sobre la organización territorial del Estado" (Arza y Mari-Klose, 2014, p. 40). Estas asunciones llevan a explicar el movimiento independentista como un movimiento de "abajo hacia arriba", es decir, de los ciudadanos a las élites. Esta hipótesis, a nuestro juicio, es contrafáctica. Todos los datos de los que disponemos sostienen y confirman la situación contraria, pero esto se comentará seguidamente.

La explicación instrumentalista del nacionalismo:

En lo que respecta fundamentalmente al análisis del nacionalismo catalán y de lo que se llama el proceso soberanista en Cataluña, existe otra línea de investigación fundamental para explicar ese fenómeno de naturaleza empírica que se centra en una aproximación modernista ${ }^{8}$ y que asume, en gran medida, los postulados instrumentalistas de Miliband. En esta línea de investigación, que sigue la estela de Juan Linz ${ }^{9}$, pionero en este tipo de trabajos, destacan los textos de J. T. Miley $(2006 ; 2008,2013)$, Martínez Herrera y Miley (2010), De la Calle y Miley (2008); Gaviria y Miley (2013); y Martínez Herrera (2002; 2005; 2009). Estos autores sostienen, y demuestran, la hipótesis de que el nacionalismo catalán está atravesado fundamentalmente por el fenómeno de clase social en correspondencia con clivajes de naturaleza lingüística, es decir, que existe una relación de correspondencia entre la identidad nacional subjetiva, el uso de la lengua y la clase social. De tal modo que los sectores medios y altos de la estructura de clases de sociedad catalana tienden a ser mayoritariamente catalano-parlantes y a identificarse con el nacionalismo catalán. Esta perspectiva da cuenta de la fuerza del nacionalismo catalán (y movimiento secesionista), principalmente -aunque no de modo exclusivo- en función de la sobre-representación de las clases dominantes en las élites políticas catalanas, es decir, que entienden y demuestran la existencia de una clara relación de pertenencia a los sectores medio altos y altos de la sociedad de los individuos que conforman la élite política.

En términos de Miley $\left(2006,2013^{10}\right.$, 2014); De la Calle y Miley, (2008); Gaviria y Miley (2013), Martínez Herrera y Miley (2010) y de Martínez Herrera (2002, 2005, 2009), en Cataluña hay un proceso de

\footnotetext{
${ }^{7}$ Dentro de esta perspectiva (y por mencionar solo algunos trabajos de una amplísima literatura) destacan los textos de Guibernau (2002), Conversi (1997).

${ }^{8}$ Se hace referencia a un enfoque modernista de los estudios del nacionalismo.

9 Desde finales de la década de 1970 el CIS viene incluyendo la pregunta Linz-Moreno que interpela respecto la identidad nacional subjetiva. Este sentimiento identitario arroja una aproximación muy acertada de las opciones acerca de preferencias identitarias como el nacionalismo o incluso acerca del independentismo en tanto que es un concepto - el identitario- estrechamente vinculado a la nación.

${ }^{10}$ En Miley (2013) se suma a la explicación de la sobre representación las funciones de bloqueo de preferencias de los sectores de sensibilidad no catalanista que produce el sistema de partidos en Cataluña.
} 
nacionalización de "arriba hacia abajo" que encabezan las élites políticas a partir de un proceso de sobrerepresentación de esos sectores, medios-altos y altos, en las élites políticas y educativas. Del mismo modo, existen unos vínculos de la élite política y del personal con altos cargos de la administración de la Generalitat, con las clases dominantes en Cataluña (Matas, 2001).

Hay dos claras dinámicas que se producen paralelamente. La primera de estas dinámicas señala unos vínculos entre la élite político-administrativa de Cataluña y las clases dominantes de la población; y la segunda tendencia es la mayor identificación identitaria de esas élites político administrativas catalana con una identidad exclusivamente catalana o mayoritariamente catalana frente a la población de Cataluña. Esta relación entre la Generalitat de Cataluña y los sectores dominantes (altos y medio-altos) de la población se encuentra como actor destacado en la función de representación la federación CiU, que se analizará más adelante, en tanto que partido burgués.

Por todo lo anterior, podemos asumir aquí la existencia de una hegemonía social y política de los sectores altos y medios-altos de la sociedad catalana (Miley, 2013), que se refleja en las relaciones entre CiU como partido burgués y la élite política y administrativa de la Generalitat de Cataluña. Tal y como lo demuestran los trabajos de Miley (2006) y de Matas (2001) en los que se establece una correlación estrecha entre la clase dominante y la élite político-administrativa catalana, en el primero, y "el trasvase claro de las élites del partido a posiciones de élite dentro de la administración" del Estado (Matas, 2001, pp. 110-111) en el segundo.

El perfil nacionalista de las élites políticas catalanas siempre ha sido, tal y como se describió, fuertemente práctico y pactista. Ese pactismo moderaba el nacionalismo ideológico con la praxis política negociadora, en una estrategia que fue descrita por Dowling (2013) como de "pragmatismo posibilista". Si bien es cierto que el independentismo siempre ha existido como forma de manifestación política en Cataluña, nunca ha sido una fuerza política destacada. El recurso al independentismo -que tal y como expone Colomer a veces emergía retóricamente de las filas nacionalistas-, puede ser entendido como una "amenaza táctica" o bien como una "reacción exaltada de descontento" (Colomer, 1984, p.371), pero siempre dentro de una estrategia general pactista que concibió siempre a España como el único sitio pensable para Cataluña, además de fuertemente vinculado a la lógica de acumulación del Capital.

\section{Análisis y resultados: La mediación y la representación como determinantes de la autonomía relativa del Estado en el caso de Cataluña.}

Es solo a partir del concepto de autonomía relativa que se puede explicar cómo a partir de unas relaciones materiales, ideológicas e incluso familiares, tan estrechas como las ya señaladas (Miley, 2006, 2013; 
Santamaría, 2008, 2011; Ovejero Lucas, 2006, 2012) el Gobierno de la Generalitat, con CiU como actor destacado, ha optado por escorar su discurso hacia la independencia. La primera consecuencia — pero no la única- que tiene el giro hacia el secesionismo que abandera $\mathrm{CiU}$ - con el apoyo de ERC, CUP - ha establecido una brecha con esos mismos sectores dominantes de la que es directamente representante. Irreductibilidad de lo político. Rol de la Generalitat como mediador:

El rol de la Generalitat es una cuestión de carácter primordial en el análisis, dado que es el Gobierno de la Generalitat quién ejerce los roles de mediación, en los términos descritos más arriba. La forma de consolidar la hegemonía en términos gramscianos es el acceso de los sectores dominantes al Estado. Esto ha sido así en Cataluña desde 1980. Las clases dominantes han accedido a la Generalitat a través del su partido, que es CiU. Y la Generalitat de Cataluña ha mediado en favor de la lógica de acumulación del capital, hasta el año 2010, representando a los sectores dominantes. Estas funciones de mediación y representación que cohesionaban a las clases dominantes y asimilaban a las dominadas, han cambiado drásticamente.

Este cambio ocurre, en gran medida, porque es la propia Generalitat la que afronta el desafío de la independencia; no se trata de un actor cualquiera. La Generalitat es parte de la organización territorial de Estado español, a pesar de que las élites políticas nacionalistas se refieran constantemente al Estado español como un conjunto de instituciones escindidas y diferenciadas de la Generalitat de Cataluña (Ovejero, 2006 y Alonso, 2015). Por otra parte, España es un país profundamente descentralizado que ha dotado a sus Comunidades Autónomas de importantes transferencias de competencias financieras y políticas $^{11}$, transformando de ese modo a España en un país sustancialmente federal ${ }^{12}$. Estas dos características conjugadas, la de posicionarse como una entidad diferenciada y el amplio abanico competencial, tienen importantes efectos directos sobre el aumento de los apoyos sociales a la secesión, tal y como sostiene de Blas Guerrero, porque "[e]l Gobierno de la Generalitat ha impulsado un proceso de encuadramiento social, de control desde el poder, que hace difícil oír las distintas visiones ante el problema" (de Blas. El País, 8 de octubre de 2013) ${ }^{13}$.

\footnotetext{
${ }^{11}$ Las Comunidades Autónomas tiene cuatro tipos de competencias de diversa naturaleza que son: Competencias legislativas y ejecutivas exclusivas; éste es el caso de las competencias, tales como los servicios sociales, agricultura y ganadería, pesca interior, industria, comercio, turismo, juventud y deportes. Competencias para el desarrollo de la legislación del Estado central, y para la implementación de esta legislación; éste es el caso de medioambiente, política económica, educación, y salud. Competencias para la ejecución de la legislación aprobada exclusivamente por el Estado central; en el caso de empleo y formación. Competencias legislativas y ejecutivas, junto con el Estado central pueden llevar a cabo las mismas acciones e iniciativas, como en el caso de las competencias en cultura.

${ }^{12}$ La cuestión de la naturaleza federal del Estado de las Autonomías español es un debate que ha recibido un gran número de publicaciones. Sobre este particular en esta tesis se sostiene la concepción de que "a pesar de que España no es formalmente un Estado federal, si lo es sustancial o materialmente, como así coincide en afirmarlo la mayoría de la doctrina (Aja, 2003).

${ }^{13}$ Las estadísticas del Centro de Estudios de Opinión (CEO) indican que hay un retroceso en las preferencias poblacionales sobre la independencia. EI CEO dependiente del Gobierno de la Generalitat indica que hay un retroceso en los apoyos sociales al independentismo a partir de noviembre de 2014 , según indica el "Baròmetre d'Opinió Política (BOP). 2a onada 2015 - REO 795", disponible en línea en:

http://www.ceo.gencat.cat/ceop/AppJava/pages/home/fitxaEstudi.html?colld=5468\&lastTitle=Bar\%F2metre+d\%27Opini\%F3+Pol\%EDtica+\%28BOP\%29.+2a+onad a+2015.
} 
Las modificaciones en la función de mediación y representación se producen en el ámbito estrictamente político en el que el Gobierno de la Generalitat se autonomiza de las clases dominantes a nivel social y se orienta, en este caso, hacia un cambio de los apoyos fundamentales del Gobierno de Cataluña respecto a las bases sociales que los sostienen. El Gobierno de CiU ha abandonado el apoyo de las clases altas (burguesía), al poner en riesgo sus intereses a largo plazo y se ha orientado a satisfacer a intereses de ciertos sectores intermedios (pequeña burguesía) muy sensibles a las cuestiones identitarias. Estos sectores intermedios de origen catalán y catalano-parlantes han sido históricamente muy receptivos al discurso nacionalista (Marfany, 1995).

El alejamiento de las clases dominantes tiene que ver, antes que con una falta de defensa de sus intereses, con la puesta en riesgo de la lógica del capital a largo plazo. El Gobierno subcentral parece, en este sentido, haberse autonomizado en sus fines, asumiendo elecciones que tienen poco que ver con la lógica del capital a largo plazo, sino con la propia esfera política. Es en este sentido que la independencia se planteaba como el ejercicio de máxima autonomía política. En tanto que se hace prevalecer la lógica y los intereses de las élites políticas frente a la lógica e intereses del Capital.

$\underline{\text { La relación de la clase dominante y la Generalitat de Cataluña. }}$

La federación Convergencia y Unió ${ }^{14}(\mathrm{CiU})^{15}$ es el partido burgués nacional por definición en Cataluña, en los términos de Therbon (1979) aquí citados. CiU ha sido el eje sobre el que ha gravitado la reconstrucción nacional (Dowling, 2013) de Cataluña desde 1980 hasta hoy. En palabras de José Luis Álvarez: “EI catalanismo es la plataforma de hegemonía de la burguesía de origen catalán, y CiU es su partido. Las tácticas que CiU ha elegido para mantener la iniciativa y hegemonía políticas, sin una demografía mayoritaria ni dominio electoral estable, para conseguir la máxima activación de sus bases y la máxima pasividad, cuando no subordinación, de su oposición, son una gran lección política." ${ }^{16}$ (José Luis Álvarez, El País, 23 de julio de 2013).

CiU, el partido burgués en el Gobierno de la Generalitat de Cataluña, es el partido que representa los intereses de las clases dominantes de la sociedad catalana. ${ }^{17}$. Estos vínculos, tal y como se ha comentado, tienen un origen instrumental, por las funciones de representación, pero también estructural, por la propia naturaleza de la política (lo irreductible de la política en términos de Therborn) que nos remite, también, a

\footnotetext{
${ }^{14}$ CiU era la federación de los dos partidos Convergencia Democrática de Cataluña y Unión Democrática de Cataluña que aglutinaba al nacionalismo catalán conservador en lo social y liberal en lo económico; pero se debe matizar que un sector mayoritario de Unió no adscribe a ese giro independentista de CiU y mantiene su tradicional posicionamiento confederal como vía de "encaje" de Cataluña en España. Esta tensión sobre el posicionamiento de la independencia de Cataluña y las vías para obtenerla ha llevado a la ruptura de CiU. Esta ruptura ha ocurrido mientras se redacta este artículo a mediados del año 2015.

15 Para un análisis detallado de esa formación desde sus orígenes véase Santamaría, A. (2011), Culla i Clarà (2001) y Gibernau (2002) 16 Disponible online en http://elpais.com/elpais/2012/07/23/opinion/1343038261 771040.html

17En este sentido vemos que el propio Gobierno de la Generalitat se declaró en 2010 abiertamente "business friendly". Disponible en línea en http://ccaa.elpais.com/ccaa/2014/02/15/catalunya/1392491409_519275.html
} 
las funciones de mediación y representación. Ello nos lleva a afirmar que la Cataluña democrática y su gobierno autonómico - la Generalitat de Cataluña - se han construido, en gran medida y a la medida, de la élite política perteneciente a $\mathrm{CiU}$, y que su gobierno ha sido clave en la salvaguarda de los intereses de las clases dominantes.

No obstante esos fuertes vínculos, una vez iniciado el proceso soberanista y viendo la naturaleza de las acciones del Gobierno de la Generalitat de CiU, los sectores dominantes a nivel económico de la sociedad catalana, del mismo modo que la burguesía internacional con intereses en Cataluña ${ }^{18}$, han dejado claro su escepticismo, cuando no su rechazo explícito, al llamado plan soberanista y han abogado por la negociación entre el Gobierno del España y el Gobierno de la Generalitat ${ }^{19}$. Es propio de la lógica del capital que las clases altas no apoyen proyectos que produzcan incertidumbres o una situación de inestabilidad política e institucional como la que genera un proceso de estas características.

Esta radicalización de posiciones del proceso de secesión es en sí misma el ejemplo más extremo del ejercicio de la autonomía Estatal, y es extremo porque altera, en principio, la lógica de acumulación del capital en Cataluña y en el resto de España. Y esta distancia de los intereses de la burguesía que la élite política ha tomado, ha entrado en clara contradicción - de modo discreto o no tanto- con las instituciones que representan a los sectores dominantes de la sociedad catalana y del empresariado trasnacional.

Esa alteración de la lógica del capital que presenta la secesión de Cataluña no es en modo alguno de carácter temporal y a corto término, sino que lo hace de manera indefinida y a largo plazo; sin ninguna garantía de una mejora, o tan siquiera, de un mantenimiento de las condiciones socioeconómicas e institucionales actuales, ni para las personas, ni para las empresas.

\section{El partido burgués, la Generalitat y las clases subordinadas (medias y trabajadoras):}

En Cataluña la consolidación de CiU se manifiesta en el éxito que ha tenido al cohesionar y subordinar, al menos hasta ahora, a las clases y fracciones de clase no hegemónicas, como la pequeña burguesía y a las clases trabajadoras, en lo que respecta al clivaje nacional frente al clivaje de clase (Pallares y Font, 1995).

En lo que respecta a estos sectores subordinados y su relación con CiU podemos decir que los sectores no dominantes que apoyan a CiU son los sectores intermedios, que en términos de Therborn, son la pequeña

\footnotetext{
${ }^{18}$ Puede verse en http://ccaa.elpais.com/ccaa/2014/02/11/catalunya/1392118425 106264.html el lanzamiento de la plataforma de: ¿Catalunya sensa Europa? ¡No!, su portavoz Albert Peters, literalmente ha dicho que "los políticos de vez en cuando nos escuchan, porque con los empresarios ahora no han hablado lo suficiente, ni la Generalitat ni el gobierno de España", declaraciones disponibles en línea en: http://www.europapress.tv/politica/214960/1/presentan-plataformacontra-salida-catalunya-ue.html

${ }^{19}$ Esto puede verse reflejado en las declaraciones del presidente de Foment dell Treball, Joaquim Gay de Montellà. Declaraciones disponibles en línea en http://www.europapress.es/catalunya/noticia-fomento-trabajo-detecta-menos-independentismo-empresas-catalanas-verano-20131223113619.html;

http://www.europapress.es/catalunya/noticia-gay-montella-fomento-trabajo-duda-pueda-hacer-consulta-amparo-ley-20131212185948.html;

http://www.europapress.es/economia/noticia-presidente-patronal-catalana-cree-independencia-puede-conducir-cierto-aislamiento-20130729130138.html; así como en las declaraciones del presidente de origen catalán de la patronal española Juan Rosell en http://www.lavanguardia.com/politica/20140211/54400146894/juan-rosell-independencia-catalunya-destrozo.html

Véase también una negativa directa hacia la realización de la consulta soberanista por parte de Joaquim Gay de Montellà. Declaraciones disponibles en línea en http: http://www.lavanguardia.com/economia/20140316/54403127468/joaquim-gay-de-montella-consulta.html
} 
burguesía, una parte nada desdeñable de los trabajadores de cuello blanco, es decir, dependientes, trabajadores cualificados en labores no manuales y un gran número de funcionarios de la Generalitat de Cataluña.

Estos sectores intermedios se han favorecido de la acción de la Generalitat en lo que a empleos públicos se refiere. Tal y como sostiene Ovejero Lucas $(2006$ y 2012) y Santamaría $(2008,2011)$ las políticas de empleo público en Cataluña implementadas desde la Generalitat, que exigen un conocimiento de la lengua catalana como requisito indispensable para acceder a las plazas de funcionariado público, cumple la función de cierre social (Parkin, 1984) para mantener la exclusividad de acceso a esa fuente de renta y prestigio y, por otra parte, para reducir las oportunidades de acceso a las clases bajas que en su mayor parte son de habla castellana.

Los sectores intermedios encuentran, en el requisito de uso del catalán, un mecanismo para asociar el "progreso social", es decir, la movilidad social ascendente, al dominio del catalán. Ello explica "la adhesión de amplios estratos de la pequeña burguesía al imaginario simbólico pujolista ${ }^{20}$ que, al fin y al cabo, les aseguró puestos de trabajo y prestigio social" (Santamaría, 2008, p.28).

Por otra parte, esos mismos sectores intermedios (pequeña burguesía y trabajadores de cuellos blanco catalanoparlantes) son los destinatarios de las políticas de naturaleza identitaria que tienden a funcionar como herramienta para el cierre social a favor de estos sectores. Quedan así vinculadas las políticas identitarias y las políticas de empleo llevadas cabo por la Generalitat de Cataluña, que favorecen a esos sectores intermedios particularmente sensibles a los reclamos indentitarios.

En lo que respecta a los cambios específicos en las relaciones de representación podemos decir que ha habido un cambio en tres circunstancias claves: el cambio de alianzas parlamentarias y estratégicas de CiU, que pasó de aliarse con el PP entre los años 2010 al 2012, a aliarse con ERC a partir del año 2012 en adelante; la relevancia en el proceso soberanista que el Gobierno de la Generalitat le ha otorgado a las entidades independentistas Asamblea Nacional Catalana (ANC), Omnium Cultural (OC) y Asociación de Municipios por la Independencia (AMI); y por último, la ruptura de la propia federación CiU; en la que Convergencia Democrática de Cataluña y Unión democrática de Cataluña, se escinden en función de las discrepancias por las formas y la continuidad del proceso soberanista.

$\mathrm{Si}$ bien se mantienen las formas en que se recluta al personal dirigente, tanto en CiU como en la Generalitat, manteniendo los vínculos que señalan Miley (2006, 2013, 2014), Martínez-Herrera (2002, 2009), Ovejero (2006 y 2012), y Arza y Marí-Klose (2014) entre las élites político-administrativas y las económicas; sí hay ciertos cambios en otros elementos de la representación. Estos cambios, en ambas

\footnotetext{
${ }^{20}$ Se hace referencia al fundador de CiU y Presidente de Cataluña desde 1980 hasta 2003, Jordi Puyol.
} 
funciones, se producen principalmente en el ámbito de las políticas identitarias, educativas y culturales, mientras que, en el ámbito de lo estrictamente económico, se ha producido un cambio que es sustancial, ejemplo de ello es el cambio de postura de Mas que en 2010 declara a su Gobierno "business friendly" para dos años más tarde exigir a las asociaciones de empresarios que participen del proceso y "no pasen de la política" (La vanguardia, 14 de febrero de 2014) ${ }^{21}$ después de haber recibido críticas de los empresarios y de las asociaciones que los nuclean, por la deriva soberanista, en más de una oportunidad ${ }^{22}$, tal y como ya se ha reseñado.

El giro en la representación se denota también, en la alianza estratégica de CiU que pasó de una corta legislatura de dos años y de gobierno en minoría con apoyos puntuales del PP, a una alianza con ERC, un partido históricamente vinculado a los sectores de la pequeña burguesía catalanista (Marfany, 1995) que desde finales de la década de los ochenta es abiertamente independentista (Guibernau, 2002).

Destaca, además, el protagonismo concedido por el Gobierno del Generalitat a las asociaciones civiles en favor de la independencia ANC, OC, y $\mathrm{AMI}^{23}$, en lo referente a la organización de los actos de apoyo a la secesión, así como en la formación de las candidaturas de este proceso soberanista, en tanto que "representantes de la sociedad civil" (Alonso, 2015). ${ }^{24}$

Por último, un elemento muy reciente, que se produce durante la redacción de este artículo es la ruptura de la federación CiU por la desavenencia respecto de la forma institucional que debe tener la continuidad del proceso soberanista. Mientras Convergencia Democrática de Cataluña (CDC) busca la vía de convertir la próxima elección de gobierno regional en una elección plebiscitaria sobre la independencia, por su parte, Unión Democrática de Cataluña (UDC), no sin una importante fractura interna, opta por una vía legal de convocatoria a un referéndum. La ruptura deja a CDC sin el contrapeso de un partido tradicional y conservador en lo social que era la UDC. Los democristianos de Unión, por otra parte, nunca vieron con buenos ojos la alianza estratégica con ERC y se sintieron incómodos con ese giro hacia los sectores medios profundamente nacionalistas a los que se dirigieron las funciones de mediación y representación, que aquí se han señalado.

Síntesis de los cambios en la relación de mediación y en la representación:

\footnotetext{
21 Disponible en línea en: http://www.lavanguardia.com/politica/20140214/54401278248/mas-reclama-la-implicacion-del-empresariado-catalan-en-el-procesosoberanista.html

${ }^{22}$ Véase el artículo de La Vanguardia, 11 de febrero de 2014, en el que el Presidente de la CEOE sostiene que la independencia de Cataluña "sería un destrozo". Disponible en línea en http://www.lavanguardia.com/politica/20140211/54400146894/juan-rosell-independencia-catalunya-destrozo.html

${ }^{23}$ La ANC es una asociación por la independencia de Cataluña muy cercana a ERC que ha apoyado todas las decisiones y movimientos de CiU; por su parte OC es una asociación que ha devenido en abiertamente independentista, su perfil es profundamente conservador y vinculada a los sectores medios-altos y altos de la sociedad catalana, por otra parte es cercana a CiU; AMI, nuclea los municipios cuyos gobiernos se han declarado a favor de la independencia.

${ }^{24}$ Es menester mencionar que la representatividad social que se asignan, y que les asigna, desde el Gobierno de la Generalitat, en la toma de decisiones es de más que dudosa legitimidad en tanto que son asociaciones civiles y no están integradas dentro del sistema democrático como agentes de decisión.
} 
Dentro de las estrategias de alianzas de gobierno, la élite política de CiU, en pos de su autonomía política, pasa a establecer los apoyos fundamentales del Gobierno de la Generalitat sobre los sectores intermedios de la sociedad, autonomizándose de este modo, de la clase dominante y hegemónica - al menos de forma relativa-, cambiando así la dinámica de las relaciones de fuerzas que sostiene al gobierno y su ejercicio de mediación y de representación.

De este modo, el nacionalismo de naturaleza sub-estatal o periférico cumple aquí el rol de partido burgués nacional que señala Therborn (1979), en tanto que es uno de los factores que utiliza este tipo de partidos como recurso ideológico para movilizar al electorado y atraer a los sectores intermedios. CiU en coalición con ERC ha ahondado en el clivaje nacional, por sobre otras fracturas como la de clase, tal y como se ha citado (Pallares y Font, 1995; Pallares, 2000).

Therborn sostiene que "[e]l nacionalismo que en algún tiempo fue un elemento esencial de la revolución burguesa, se ha convertido en una potente arma de la dominación capitalista, y ha mostrado también un cierto atractivo para algunos sectores de la clase obrera. [...] Los partidos burgueses se las han arreglado, en general, para aparecer ante sus países como el partido nacional" (Therborn, 1979, p.233).

CiU históricamente ha encarnando el discurso nacionalista y se ha transformado en el partido "nacional" de Cataluña, quien defiende sus intereses, y quien mejor los representa, en el sentido que menciona Therborn. Es a partir de la fuerza del discurso nacionalista como CiU (y el nacionalismo catalán en general) que han podido subordinar la cuestión social (de clase) a la cuestión nacional. Esta subordinación de la temática social - que se aprecia antes que nada en el diagnóstico de la situación- ha tenido como efecto la subordinación y la desmovilización de muchos individuos pertenecientes a los sectores bajos y medios-bajos de la estructura social catalana a la visión hegemónica del nacionalismo de CiU.

Dentro de la dinámica de los procesos de mediación hemos visto, además, cómo el partido burgués encarna también algunos peligros para la clase dominante. El primero de estos peligros es que la élite política sea cada vez menos accesible y menos dócil con la clase dominante, ampliando de este modo el margen de autonomía relativa; el segundo de esos peligros, en palabras de Therborn es que "por encima de todo, existe el peligro de que el partido burgués de masas conceda una importancia excesiva [...] a la pequeña burguesía. [...] Puede ocurrir que la intransigencia de ciertos sectores de la pequeña burguesía ponga en peligro la mediación del poder respecto de la clase obrera" (Therborn, 1979, p.234).

El cambio en las funciones de mediación y representación ha generado una situación de doble peligro en Cataluña, tal y como señala Therborn. El giro en la mediación y representación que favorece a la pequeña burguesía (sectores medios) en detrimento de las clases dominantes, supone un claro riesgo para los sectores bajos y medios bajos (clase obrera, en términos de Therborn) que no se ven interpelados en 
función de las cuestiones sociales, sino en las cuestiones de naturaleza identitaria centrales para el nacionalismo catalán, teniendo en cuenta que la ascendencia de este sector es mayoritariamente migrante (o descendiente de migrante) del resto de España y castellano parlante.

Nuevas circunstancias que permiten el cambio del posicionamiento de las élites políticas:

Este giro en la dinámica de apoyos de CiU que quita peso específico a los sectores altos y medios-altos de la sociedad catalana y redirecciona los apoyos hacia los sectores intermedios, es potenciado a su vez, por la irrupción de uno de los tres escenarios de incertidumbre que, según Block (1980, p. 232), aumentan la autonomía del Estado; y que son los casos de guerra, depresión económica y reconstrucción.

Siguiendo a Block (1980) podemos decir que la depresión económica, vista y vivida en España en general, y en Cataluña en particular, como un fenómeno de una intensidad muy particular, hace que la esfera de autonomía del poder de la Generalitat y de la élite política aumente hacia espacios de mayor discrecionalidad. Es de destacar que este escenario de depresión económica afecta fundamentalmente a los sectores de menores ingresos, es decir, a los sectores bajos o subordinados y medios de la sociedad.

En ese contexto de depresión económica, el Gobierno de la Generalitat ha implementado dos políticas en paralelo; por una parte se han aplicado una serie de políticas neoliberales en el ámbito económico y social, propiciando la reducción del gasto público, restringiendo el empleo público, bajando salarios, flexibilizando condiciones de labor, etc. (de todas estas decisiones la Generalitat responsabiliza directamente al Gobierno del Estado central como parte del argumento de la deficiente financiación y del expolio fiscal ${ }^{25}$ ) y, por otra parte, se profundiza el perfil identitario de las políticas. En otras palabras, mientras se conciertan, privatizan y externalizan servicios públicos vinculados a la salud, la asistencia y la educación (Santamaría, 2011), por otra parte se profundizan los reclamos de naturaleza identitaria. En este escenario asistimos a una radicalización del discurso de la élite política nacionalista catalana que reivindica -ya no solo la mejora de la financiación tal y como ocurría en el pasado- sino la secesión de Cataluña en un momento de depresión económica a la que se la han dado respuestas neoliberales (Dowling, 2013).

Esta combinación de políticas de recortes sociales con políticas de promoción de la independencia, ha logrado diluir en gran medida los reclamos sociales de las clases trabajadoras y de las organizaciones que las representan, al anteponer con éxito el eje identitario (o nacional) al ideológico izquierda-derecha.

Los límites de la autonomía relativa del Estado:

Existen, por otra parte, dos dinámicas institucionales que refuerzan la autonomía relativa de la Generalitat de Cataluña, pero que por motivos de extensión solo se enunciarán de modo sintético, que son las dinámicas

\footnotetext{
${ }^{25}$ Para mayor detalle en la forma de estructurar los argumentos véase el paper presentado en el XI Congreso de AECPA en 2013 por Zambelli, S. "Cambios y continuidades del nacionalismo en Cataluña. El proceso soberanista desde una perspectiva ideológica", disponible en la web en: http://www.aecpa.es/congresos/11/ponencias/605/
} 
institucionales centrífugas y el federalismo competitivo: el federalismo competitivo del Estado de las Autonomías (Balfour y Quiroga, 2007) propició -y propicia - reclamos constantes de mayores cuotas de autogobierno y poder por parte de las élites regionales de las diferentes Comunidades Autónomas frente al Estado central. Estas constantes reclamaciones de las élites, en última instancia, ponen también en cuestión el marco de la propia autonomía; de este modo, nunca queda definido el final (Núñez Seixas, 1999; Keating, 1996) o el cierre de las reclamaciones de transferencias por parte del Estado central a las Autonomías. La autonomía del Gobierno de la Generalitat se ha visto ampliada, en ese sentido, por la capacidad de concentración de poder que le ha otorgado el desarrollo de la Constitución y de los dos Estatutos de Autonomía (1979 y 2006), en lo referente a la transferencia de competencias desde el Estado central a la Comunidad Autónoma de Cataluña. Estas transferencias, fundamentalmente las vinculadas con la educación, poseen una peso relevante en tanto que aparatos ideológicos (Therborn, 1987; Althusser, 2003) en el ejercicio de las funciones ideológicas (además de las técnicas y políticas) del Estado, tal y cómo lo atestigua Aspachs-Bracons et al (2008b; 2008a). La segunda dinámica institucional que amplía la autonomía es la acción de las élites nacionalistas en una dinámica institucional centrífuga, que prima el éxito en las dinámicas de competición regional (Ovejero, 2006, 2012; Balfour y Quiroga, 2007). La competencia en ágoras más pequeñas y autonomizadas de la del Estado central aumenta la autonomía de la Generalitat.

Otro factor de naturaleza estructural, que determina el límite de esa autonomía de lo político es la ya comentada dinámica de acumulación del capital. El límite de la autonomía, entendido desde la óptica estructural de Poulantzas y de Therborn, se relaciona con la naturaleza capitalista del Estado en sí. Es aquí en donde radica la propia limitación de la autonomía, es decir, su relatividad. En lo que respecta al análisis concreto del caso empírico que nos ocupa, podemos decir que el Gobierno de la Generalitat, dada la presión estructural a la que se verá sometido, es probable que se oriente a resolver a favor de los sectores dominantes las contradicciones entre la élite política con la clase que la sustenta. Con todo lo anterior, es muy probable que las presiones de los grupos de poder que responden a las fracciones hegemónicas de las clases dominantes, ${ }^{26}$ sumada a la propia presión que la estructura ejerce sobre el Estado, tienda a constreñir la autonomía de lo político.

Por otra parte, y desde una perspectiva más instrumental, las presiones de los grupos de poder sobre el Gobierno de la Generalitat son la manifestación directa de la capacidad de las clases dominantes de censurar y hasta reprender a las élites políticas, cuando se pone en juego la lógica de la acumulación del capital a largo plazo. Las clases dominantes pueden presionar a las élites gubernamentales para que las decisiones sean tomadas en un sentido determinado; de este modo la autonomía disminuye y la relación

${ }^{26}$ Véase las notas $12,13,14$ y 15. 
entre el gobierno y clases tiende a ser más lineal. Esta capacidad de alineamiento hace referencia a la determinación - siempre en última instancia- de la base material sobre la superestructura.

Por otra parte, existe otra cuestión que limita la autonomía de la Generalitat que es la propia estructura demográfica e identitaria de Cataluña que se aleja materialmente de la proyección que de ella hace la élite política nacionalista (Miley, 2006, 2013, 2014; Ovejero, 2012, Alonso, 2015) cuestión que ha sido, y es, fuente de muchas publicaciones.

Sin acontecimientos que rompan la lógica de las relaciones estructurales, es posible aventurar que esas determinaciones que limitan la autonomía relativa que se han comentado, puedan previsiblemente ir imponiéndose a las acciones derivadas del ánimo secesionista de gran parte de la élite política catalana.

\section{Discusiones y Conclusiones:}

En el presente trabajo se ha querido abordar el proceso secesionista en Cataluña analizado a partir del concepto de la autonomía relativa del Estado. Se ha intentado responder a dos preguntas ¿qué ha posibilitado que las élites políticas catalanas hayan radicalizado sus posiciones nacionalistas al llevar adelante el proceso soberanista en Cataluña, poniendo en riesgo los intereses de los sectores dominantes a la que la élite política catalana ha estado siempre especialmente vinculada? ¿En qué circunstancias son posibles esos cambios?

A lo largo del texto se pretende haber esclarecido que las aproximaciones de naturaleza instrumental como las de Miley y Martínez-Herrera, si bien son ciertas, acertadas y describen fehacientemente fenómenos sociales, tienden hacia un cierto voluntarismo que impide profundizar más allá de las relaciones interpersonales de la élite y la burguesía ${ }^{27}$. En contrapartida, la perspectiva estructural de Therborn nos permitió ahondar y completar el análisis del proceso soberanista, a partir de las funciones estatales de representación y mediación que son las que condicionan la autonomía del Gobierno de la Generalitat. Se ha distinguido, además, como elemento relevante la especificidad de lo político, que en el caso catalán se manifiesta en una consolidación de la élite política conservadora mediante el formato de representación del partido burgués que ha encarnado CiU. Por otra parte, se han señalado dos condicionantes institucionales como son las dinámicas del federalismo competitivo y de la competición centrífuga que enmarcan y determinan tendencias generales de la acción política.

A partir de lo anterior, se ha propuesto como hipótesis central que el proceso soberanista sólo es posible a partir de un aumento de la autonomía relativa del Gobierno de la Generalitat de Cataluña y que ese

\footnotetext{
${ }^{27}$ Incluyendo la explicación complementaria de Miley (2013) que relaciona el diseño institucional del sistema de partidos catalanes con el bloqueo de las preferencias de una parte de la población de Cataluña.
} 
aumento se produce por un cambio en las funciones de mediación que consiste en una modificación del peso que otorga el Gobierno de la Generalitat a sus apoyos, desde la clase dominante a los sectores intermedios.

Paralelamente se produce un cambio en la representación con la relevancia de los sectores intermedios (la pequeña burguesía en términos de Therborn) representados por las asociaciones pro-independentistas OC, ANC y AMI que han sido posicionadas por el Gobierno de la Generalitat y las élites políticas nacionalistas como los representantes de "la sociedad civil". A ello se ha sumado la estratégica alianza con ERC a ruptura de la propia federación de Convergencia y Unión.

Se ha propuesto, además, un análisis de contexto, siguiendo a Block (1980), quien sugiere que los períodos de depresión económica amplían la autonomía estatal y dan un mayor margen de discrecionalidad a las decisiones de los gobiernos.

Por último, se ha intentado ofrecer una serie de condicionantes del límite de la autonomía, la ya citada depresión económica, las presiones propias de la estructura sobre el Estado, la determinación económica, en última instancia, y la demografía. Estas condicionantes no van todas en el mismo sentido y generan tensiones entre sí para constreñir o ampliar la autonomía relativa.

El análisis de la autonomía relativa a partir de las funciones de representación y mediación del Gobierno en Cataluña ha permitido dar cuenta de algunos de los mecanismos de naturaleza estructural que han posibilitado que las élites político-administrativas tomen decisiones a favor de la independencia de Cataluña, pero que atentan contra la lógica del Capital a largo plazo y bajo qué condiciones ello ha sido posible. 


\section{Bibliografía:}

AJA, E. (2003). El Estado Autonómico: federalismo y hechos diferenciales. Madrid: Alianza Editorial.

ALONSO, M. (2015). El catalanismo, del éxito al éxtasis. I. La génesis de un problema social. España: El viejo Topo.

ALTHUSSER, L. (2003). Ideología y aparatos ideológicos de estado. Buenos Aires: Nueva Visión.

ARZA, j y MARI-KLOSE, P. (2014). ¿La voluntad de un pueblo? En Arza, J. y Coll, J. Cataluña. El mito de la secesión. Desmontando las falacias del soberanismo. España: Almuzara.

ASPACHS-BRACONS, O., CLOTS-FIGUERAS, I., MASELLA, P. Y COSTA-FONT, J. (2008a). Compulsary Language Educational Policies and Identity Formation. Journal of the European Economic Association 6 (2-3): 434-444. ASPACHS-BRACONS, O., CLOTS-FIGUERAS, I., MASELLA, P. Y COSTA-FONT, J. (2008b). The effect of Language at School on Identity and Political Outlooks. EUI Working Papers 36.

BALFOUR, S. Y QUIROGA, A. (2007). España reinventada. Nación e identidad desde la Transición. Barcelona: Península.

BLOCK, F. (1980). Beyond Relative Autonomy: State Managers as Historical Subjects. Socialist Register, 14, 1980, 227- 242.

BORÓN, A. (2003). Estado, capitalismo y democracia en América Latina. Buenos Aires: Clacso.

CODATO, A., Y PERISSINOTTO, R. M. (2010). Marxism and elitism: two opposite social analysis models? Revista Brasileira de Ciências Sociais, 5(SE), 0-0. Disponible on line en http://socialsciences.scielo.org/scielo.php?script=sci_arttext\&pid=S0102-

\section{$\underline{69092010000100003 \& \operatorname{lng}=e n \& n r m=i s o}$}

COLOMER, J. M. (1984). Espanyolisme i catalanisme: la idea de nació en el pensament pollític català (19391979). Barcelona: L’Avenç.

CONVERSI, D. (1997). The Basques, the Catalans, and Spain: Alternative Routes to Nationalist Mobilization. London: Hurst

CULLA I CLARÁ, J. (coord.) (2001). El pal de paller. Convergencia democrática de Catalunya (1974-2000). Barcelona: Portic

DE LA CALLE, L., y Miley, T. J. (2008). Is there more assimilation in Catalonia than in the Basque Country? Analysing dynamics of assimilation in nationalist contexts. European Journal of Political Research, 47(6), 710736.

DOWLING, A. (2013). La reconstrucción nacional de Catalunya, 1939-2012. Barcelona: Ediciones de Pasado y Presente 
DUHALDE, S. (2008). "Un debate epistemológico sobre el Estado capitalista. La polémica MilibandPoulantzas". Kairos. Revista de Temas Sociales, Publicación de la Universidad Nacional de San Luis, Año 12. № 21

ETHERINGTON, J. (2003). Nationalism, National Identity and Territory. The Case of Catalonia. Tesis Doctoral. GARVÍA, R. Y MILEY, T. J. (2012). Language Policies and Language Ideologies in Contemporary Catalonia. Working Papers Online Series. Estudio/Working Paper 143/2012. Universidad Carlos III de Madrid, disponible on line en www.uam.es/wpcpolitica Estudio/Working Paper 143/2012

GUIBERNAU, M. (2002). Nacionalisme Català. Barcelona: Portic

KEATING, M. (1996). Naciones contra el estado: el nacionalismo de Cataluña, Québec y Escocia. Barcelona: Ariel.

LINZ, J. (2008). Obras escogida. Volumen II. Nación, Estado, lengua. Madrid: Centro de Estudios Constitucionales.

LACLAU, E., Y MOUFFE, C. (1987). Hegemonía y estrategia socialista. Madrid: Siglo XXI.

MARFANY, J. L. (1995). La cultura del catalanisme: El nacionalisme catala`als seus inicis. Barcelona: Editorial Empúries.

MARTÍNEZ-HERRERA, E. (2002). From Nation-Building to Building Identification with Political Communities: Consequences of Political Decentralisation in Spain, the Basque Country, Catalonia and Galicia, 1978-2001. European Journal of Political Research №. 41.

- (2005). The effects of Political Decentralisation and Support for Political Communities. A multivariate longitudinal and Cross-Sectional Comparison of the Basque Country, Catalonia, Galicia, Quebec and Scotland. Dissertation/Thesis. Florence: European University Institute.

- (2009). Federalism and Ethnic Conflict Management: Rival Hypotheses, the Attitudinal Missing Link and Comparative Evidence In New Directions in Federalism Studies, eds. J. Erk and W. Swenden. London: Rou.

MARTÍNEZ-HERRERA, E. Y MILEY, T. J. (2010). The constitution and the politics of national identity in Spain. Nations and nationalism, 16(1), 6-30.

MATAS, J. (2001). Convergència Democràtica de Catalunya, partit de Gobierno. En Culla, J. B.: El pal de paller. Convergència Democràtica de Catalunya (1974-2000). Barcelona: Portic.

MILEY, T. J. (2006). Nacionalismo y política lingüística: el caso de Cataluña. Madrid: Centro de Estudios Políticos y Constitucionales.

- (2008). Who are the Catalans? Language, identity and assimilation in contemporary Catalonia. Center for European Studies, Harvard University. Working Paper Series, 158. 
- (2013). Blocked Articulation and Nationalist Hegemony in Catalonia. Regional \& Federal Studies, 23:1, 726

- (2014). "Democratic Representation and the National Dimension in Catalan and Basque Politics". International Journal of Politics, Culture, and Society, 27(3), 291-322.

MILIBAND, R. (1978). Marxismo y política. Madrid: Siglo XXI.

- (1997). El Estado en la sociedad capitalista. Madrid: Siglo XXI.

NÚÑEZ SEIXAS, X. (1999). Los nacionalismos en la España contemporánea (siglos XIX y XX). Barcelona: Hipòtesi.

OVEJERO LUCAS, F. (2006). Contra Cromagnon. Nacionalismo, Ciudadanía y democracia. Madrid: Montesinos.

- (2012). La trama estéril. Izquierda y nacionalismo. Madrid: Montesinos.

PALLARÉS, F., Y FONT, J. (1995). The autonomous elections in Catalonia (1980-1992). Barcelona: Institut de Ciències Polítiques i Socials.

PARKIN, F. (1984). Marxismo y teoría de clases. Una crítica burguesa. Madrid: Editorial Espasa-Calpe.

POULANTZAS, N. (1969). Poder político y clases sociales en el Estado capitalista. México: Siglo XXI.

SANTAMARÍA, A. (2008). La juventud catalana se polariza. El Viejo Topo, El, (251), 27-31.

- (2011). Els origens de Convergencia Democràtica de Catalunya. Barcelona: El viejo topo.

TARCUS, H. (1991). Introducción al debate Miliband-Puolantzas. En Miliband, R., Poulantzas, N. y Laclau, E.: Debates sobre el Estado Capitalista. Buenos Aires: Imago Mundi.

THERBORN, G. (1979). ¿Cómo domina la clase dominante? Madrid: Siglo XXI.

- (1987). La ideología del poder y el poder de la ideología. Madrid: Siglo XXI

THWAITES REY, M. (2007). Complejidades de una paradójica polémica: estructuralismo versus instrumentalismo. En Thwaites Rey, Mabel (comp.). Estado y marxismo: un siglo y medio de debates. Buenos Aires: Prometeo.

WRIGHT, E. O. (1983). Clase, crisis y Estado, Editorial. Siglo XXI: Madrid 